\section{Modeling Carbon Footprints of Organic Orchard Production Systems to Address Carbon Trading: An Approach Based on Life Cycle Assessment}

\author{
Girija Page $^{1,2}$, Terry Kelly, Maria Minor, and Ewen Cameron \\ Institute of Natural Resources, Massey University, Private Bag 11222, \\ Palmerston North 4442, New Zealand
}

Additional index words. carbon footprinting, LCA, organic orchard systems, carbon trading

\begin{abstract}
Carbon footprint is widely accepted as an indicator of greenhouse gas emissions and global warming. Modeling carbon footprints based on life cycle assessment is applied as a way to evaluate the net contribution of greenhouse gases to the atmosphere from orchard production systems over one growing year. This net balance approach considers the sources and sinks of carbon and therefore provides a better reflection of an orchard system's net contribution to climate change. Carbon footprinting of organic kiwifruit and apple production systems in New Zealand indicated that the studied systems had a net sequestration from 2.4 to $5 \mathrm{t}$ of $\mathrm{CO}_{2} \mathrm{e} / \mathrm{ha} / \mathrm{year}$ and therefore can be potentially considered as carbon sinks under the Kyoto Protocol. This finding implies that the organic kiwifruit and apple orchardist can gain a monetary benefit by earning carbon credits. However, further research to improve and validate this approach is essential before it can be practically used for decision-making at the orchard level and for policymaking at the national level.
\end{abstract}

Global warming, which is caused by increasing amounts of greenhouse gases in the atmosphere, has been identified as one of the greatest environmental challenges facing the sustainability of humankind and the ecosystems in the recent times (Millennium Ecosystem Assessment, 2005). In response to the concerns over increasing greenhouse gas emissions (GHG), "carbon footprints" are widely understood in the local vernacular as an indicator of global warming. Carbon footprints are expressed in units of $\mathrm{CO}_{2} \mathrm{e}$ (carbon dioxide equivalent emissions); $\mathrm{GHG}$ other than $\mathrm{CO}_{2}$ are expressed in terms of their global warming potential in relation to $\mathrm{CO}_{2}$ (Lynas, 2007; Wiedmann and Minx, 2007).

Estimating carbon footprints of agricultural production systems is becoming an important issue for carbon trading internationally and more so in New Zealand. The New Zealand agricultural sector will be included

Received for publication 21 July 2010. Accepted for publication 2 Dec. 2010.

This study was funded by Massey University and Cecil Elliot Trust, New Zealand.

I thank the participating orchardists and the staff of the Institute of Natural Resources, Massey University, in particular, Terry Kelly, Ewen Cameron, and Maria Minor. I have exercised freedom in designing the research, interpreting the data, and making the decision to publish the results.

${ }^{1}$ Current Address: University of Western Sydney, Locked Bag 1797, Penrith South DC 1797, NSW, Australia.

${ }^{2}$ To whom reprint requests should be addressed; e-mail G.Page@uws.edu.au. under the government's Emissions Trading Scheme (ETS) from 2015 (New Zealand Government, 2009). Agriculture contributes close to $50 \%$ of New Zealand's GHG emissions (Ministry for the Environment, 2005). Identification of the source of GHG emissions from agriculture and their quantification is a necessary precursor to reduce and mitigate these emissions. Organic kiwifruit and apples are an important export activity within the horticulture industry, which helps develop New Zealand's clean and green image in many overseas markets (HortResearch, 2007). Although it is suggested that carbon balance (sink and source) is a better indicator of net contribution to GHG (Kerckhoffs and Reid, 2007; OECD, 1999), earlier attempts of life cycle assessment (LCA) and carbon footprinting of fruit production systems have not considered carbon balance as a result of lack of methodology (Milà i Canals, 2003). In our study, we consider carbon sequestration and emissions of the orchard production system within LCA-based carbon footprinting. This proposed method is illustrated using two case studies of organic kiwifruit and apple systems in New Zealand. The results from the case studies are described in the context of current developments in carbon trading, and the relationship of the proposed method with the published standards of carbon footprinting is discussed.

\section{Materials and Methods}

Approach to carbon footprinting of orchard production systems. An orchard production system is both a source and a sink of $\mathrm{CO}_{2}$ equivalent emissions (Audsley, 1997; $\mathrm{OECD}, 1999$ ). The $\mathrm{CO}_{2} \mathrm{e}$ emissions occur from the use of management inputs and from the orchard soil (Fig. 1). Direct emissions occur from the burning of fossil fuels that are used to run machinery at the orchard. Indirect emissions occur from fossil fuel energy consumed in the production of inputs such as fertilizers, irrigation equipment, tree support system, other equipment, and machinery (Dalgaard et al., 2001; Shepherd et al., 2003; Stolze et al., 2000). $\mathrm{CO}_{2} \mathrm{e}$ emissions from the orchard soil occur through emissions of nitrous oxide and carbon dioxide from the decomposition of soil organic matter (Di and Cameron, 2002). The soil organic matter includes the biomass recycled to the orchard soil from the pruned wood and leaves, decomposing fine roots (Kroodsma and Field, 2006) as well as the compost (when applied by the grower) (Shepherd et al., 2003). Orchard systems also act as sinks of $\mathrm{CO}_{2}$ in standing biomass and soil through photosynthesis and in compost, which temporarily stores carbon (Fig. 1) (Kroodsma and Field, 2006; OECD, 2001; Shepherd et al., 2003). The $\mathrm{CO}_{2}$ ratio is estimated as the ratio of $\mathrm{CO}_{2}$ e sequestration to $\mathrm{CO}_{2}$ e emissions, which indicates whether the orchard is a net source or sink of carbon. $\mathrm{A} \mathrm{CO}_{2}$ ratio above one indicates that the orchard system is a net sink of carbon.

Application to organic orchard systems. The described approach to carbon footprinting was applied to three model organic fruit production systems: kiwifruit (500 vines/ha); semi-intensive apple (800 trees/ha); and an intensive apple system (1250 trees/ha) over a typical production year. The model organic orchard systems were based on information gathered from five commercial kiwifruit and apple orchards, which are in full bearing age. The key description of the model organic orchard systems is presented in Table 1. Information was gathered by interviewing the growers on the key orchard management practices (use of machinery, equipment, fertilizer, compost, and spray materials), the way pruned wood and leaves were disposed, and the way the orchard understory was managed over a typical production year. The studied orchards were located in the Bay of Plenty region (organic kiwifruit) and the Hawke's Bay region (organic apples), which are, respectively, the largest kiwifruit- and apple-producing regions of New Zealand (Statistics New Zealand, 2006).

Key inputs of an orchard system were considered based on physical energy-material flows (Meul et al., 2007). Carbon footprints of the model orchard systems were expressed per hectare. Carbon acquisition and release from biomass were not assumed in a steadystate (Steady-state assumes that acquisition of $\mathrm{CO}_{2}$ by plant biomass balances the release of $\mathrm{CO}_{2}$ to the atmosphere) because not all the biomass is mineralized into $\mathrm{CO}_{2} \mathrm{e}$ in the same year; a part of the biomass is mineralized much more slowly over a period of years (Audsley, 1997; Rabl et al., 2007). Hence, carbon storage and release is accounted from the orchard plant (wood, stem, leaves, and fine roots) within a production year. Carbon stored in the fruit is assumed to be released 
back to the atmosphere in the same year and therefore excluded from the analysis. Indirect $\mathrm{CO}_{2} \mathrm{e}$ emissions (arising from the use of capital inputs) were allocated annually based on the respective average working life of the machinery/equipment following Wells (2001). The global warming potential for nitrous oxide was expressed over 100 years in relation to carbon dioxide (BSI, 2008).

Carbon footprint of the orchard production system was modeled using STELLA ${ }^{\circledR}$ modeling software and Overseer ${ }^{\circledR}$ nutrient budget software over one growing year. The carbon flows were characterized using appropriate $\mathrm{CO}_{2} \mathrm{e}$ coefficients, which were taken from the published literature. Key coefficients taken from the published literature are presented in Table 2. Detailed information on these coefficients and other relevant literature is presented in Page (2009). Overseer ${ }^{\circledR}$ was used to estimate the $\mathrm{N}_{2} \mathrm{O}$ emissions from the orchard soil, which formed an input to the STELLA ${ }^{\circledR}$ model to estimate total $\mathrm{CO}_{2} \mathrm{e}$ emissions.

\section{Results and Discussion}

The $\mathrm{CO}_{2}$ ratio for all three model organic orchard systems was above one, which suggests that they were net sinks of carbon emissions. The estimations of the various carbonrelated processes for the three model organic orchards are presented in Table 3. The estimated net carbon sequestration in these orchard systems ranged from 2.4 to $5 \mathrm{t} \mathrm{CO}_{2} \mathrm{e} / \mathrm{ha} /$ year. The effect of key variations in management decisions on $\mathrm{CO}_{2}$ ratio was studied using the scenario analysis. For example, the growers usually prefer to use bigger tractors $(50 \mathrm{~kW})$ in the apple systems because they are economical. Using bigger tractors means higher fuel consumption and emissions. The scenario analysis suggests that the diesel use and the associated emissions per hectare could be lowered by using a low-powered smaller tractor (using $40 \mathrm{~kW}$ instead of $50 \mathrm{~kW}$ ) although it took $10 \%$ more time to undertake the same operation. Another key management scenario that affected carbon emissions was the application of compost to the model apple systems. Compost is applied once in 4 years to the apple systems. To address this variation in the management practice, scenario analysis was undertaken in which $8 \mathrm{t} / \mathrm{ha} /$ year of bought-in compost was applied to the model apple systems. Under this scenario, there was a tradeoff between the carbon emissions and the soil carbon sequestration in both of the apple systems. Carbon emissions increased as a result of higher decomposition of organic matter from the soil as a result of the applied compost and the use of fuel to transport the compost. However, additional carbon was inputted to the orchard soil from outside the system that resulted in higher net soil carbon sequestration for that year (as compared with the base scenario in which no compost was applied). The apple systems continued to be net carbon sinks under this management scenario.

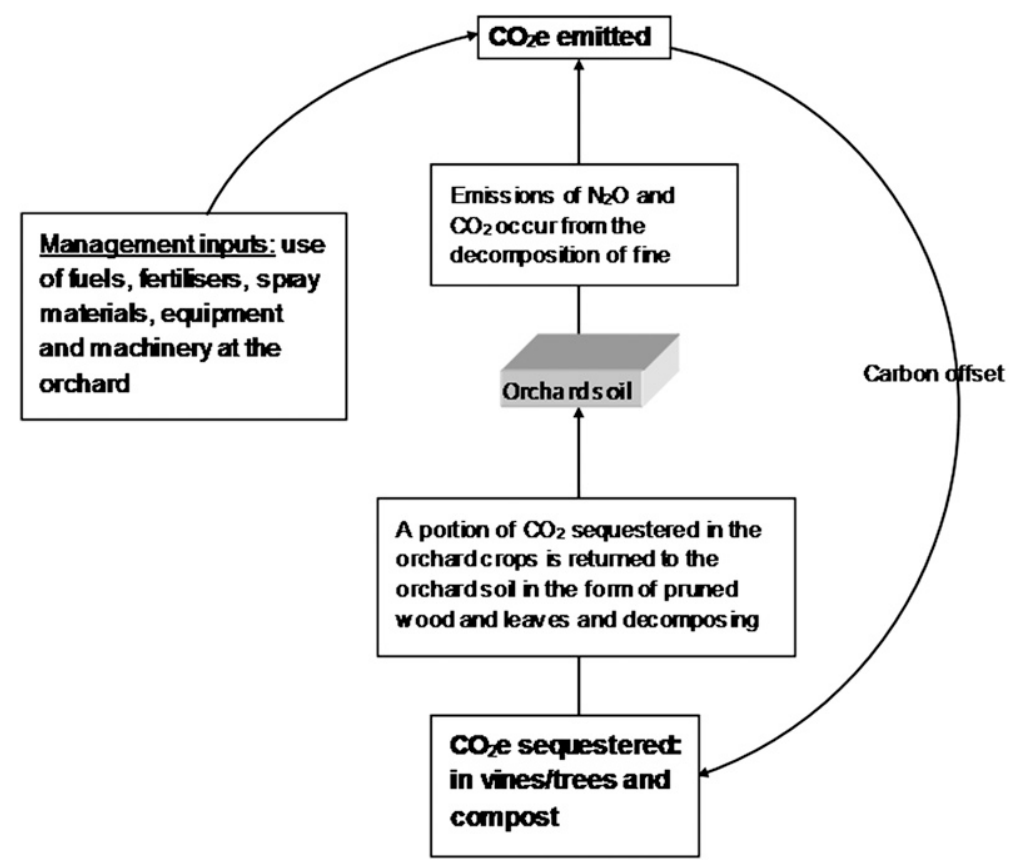

Fig. 1. Carbon cycle of an orchard system for carbon footprinting.

Table 1. Key description of model organic orchard systems for a typical production year.

\begin{tabular}{llll}
\hline \multicolumn{1}{c}{ Description } & \multicolumn{1}{c}{$\begin{array}{c}\text { Kiwifruit } \\
(800 \text { vines/ha) }\end{array}$} & $\begin{array}{c}\text { Semi-intensive apple } \\
(800 \text { trees/ha) }\end{array}$ & $\begin{array}{l}\text { Intensive apple } \\
(1250 \text { tress/ha })\end{array}$ \\
\hline Area & $5 \mathrm{ha}$ & $10 \mathrm{ha}$ & $65 \mathrm{ha}$ \\
Soil type & Volcanic loams & Alluvial loams & Alluvial loams \\
Irrigation & No & Yes & Yes \\
Lime sulfur & $\mathrm{NA}$ & $127 \mathrm{~kg} / \mathrm{ha} /$ year & $406 \mathrm{~kg} / \mathrm{ha} /$ year \\
Mineral oil & $30 \mathrm{~L} / \mathrm{ha} /$ year & $20 \mathrm{~L} / \mathrm{ha} /$ year & $40 \mathrm{~L} / \mathrm{ha} /$ year \\
Compost & $8 \mathrm{t} / \mathrm{ha} /$ year & $\mathrm{NA}$ & $\mathrm{NA}$ \\
No. of mulchings & $6 /$ year & $3 /$ year & $3 /$ year \\
Yield & $21 \mathrm{t} / \mathrm{ha} /$ year & $36 \mathrm{t} / \mathrm{ha} /$ year & $54 \mathrm{t} / \mathrm{ha} /$ year \\
No. of sprays & $7 /$ year & $29 /$ year & $36 /$ year \\
Diesel & $198 \mathrm{~L} / \mathrm{ha} /$ year & $450 \mathrm{~L} / \mathrm{ha} /$ year & $619 \mathrm{~L} /$ ha/year \\
Tractor power & $45 \mathrm{~kW}$ & $50 \mathrm{~kW}$ & $50 \mathrm{~kW}$ \\
\hline NA & & &
\end{tabular}

$\mathrm{NA}=$ not applied.

Table 2. Key coefficients taken from the published literature.

\begin{tabular}{|c|c|c|c|}
\hline \multicolumn{4}{|l|}{ Carbon emissions from inputs $\left(\mathrm{kg} \mathrm{CO}_{2} / \mathrm{MJ}\right)$} \\
\hline Diesel/mineral oil & 0.08 & & \\
\hline Rock phosphate & 0.06 & & \\
\hline Agricultural lime & 0.43 & & \\
\hline Electricity & 0.06 & & \\
\hline Machinery/equipment & 0.08 & & \\
\hline Agrichemicals & 0.08 & & \\
\hline Carbon flows of an orchard plant & $\begin{array}{l}\text { Kiwifruit } \\
\text { (500 vines/ha) }\end{array}$ & $\begin{array}{l}\text { Apple } \\
\quad(800 \text { trees/ha) }\end{array}$ & $\begin{array}{l}\text { Apple } \\
\quad(1250 \text { trees/ha })\end{array}$ \\
\hline $\begin{array}{l}\text { Kilograms } \mathrm{CO}_{2} \text { sequestered in individual } \\
\text { plant (other than fruits) }\end{array}$ & 27.46 & 29.47 & 21.05 \\
\hline $\begin{array}{l}\text { Percent } \mathrm{CO}_{2} \text { returned to the soil in the } \\
\text { form of stem, leaves and decomposing roots }\end{array}$ & 83 & 76 & 76 \\
\hline
\end{tabular}

${ }^{\mathrm{z}}$ The remaining $\mathrm{CO}_{2}$ constitutes a gain in the plant framework.

Source: Cornell University, 2007; Greer et al., 2003, 2004; Kroodsma and Field, 2006; Lakso et al., 2001; Tustin, 2007; Wells, 2001.

Carbon footprinting and carbon trading. The application of the New Zealand government's ETS at the orchard system level means that the organic growers will need to pay for the carbon dioxide they release from liquid fuel they use on the orchards (MAF, 2002). Our results suggest that all of the $\mathrm{CO}_{2} \mathrm{e}$ that is emitted from the use of fossil fuels in organic orchards in a typical production year is offset by the capture in the orchard crops and in the soil, and therefore organic orchard systems in theory could be eligible to trade carbon credits. The finding in this study reinforces the idea that orchard systems should be acknowledged as carbon sinks under the Kyoto Protocol (Horticulture New Zealand, 2007; 
Table 3. Estimates of carbon fluxes associated with various processes in the model organic orchard systems.

\begin{tabular}{|c|c|c|c|}
\hline \multirow[b]{2}{*}{ Carbon-related processes } & \multicolumn{3}{|c|}{ Organic orchard systems } \\
\hline & $\begin{array}{c}\text { Kiwifruit } \\
\text { (500 vines/ha) }\end{array}$ & $\begin{array}{c}\text { Apple } \\
\text { (800 trees/ha) }\end{array}$ & $\begin{array}{c}\text { Apple } \\
\text { (1250 trees/ha) }\end{array}$ \\
\hline Total $\mathrm{CO}_{2}$ sequestration ${ }^{z} \mathrm{t} / \mathrm{ha} /$ year & 19.6 & 23.6 & 26.3 \\
\hline $\mathrm{CO}_{2}$ sequestration in the biomass ${ }^{\mathrm{y}} \mathrm{t} / \mathrm{ha} / \mathrm{year}$ & 13.7 & 23.6 & 26.3 \\
\hline $\mathrm{CO}_{2}$ temporarily stored in the compost ${ }^{\mathrm{x}} \mathrm{t} / \mathrm{ha} /$ year & 5.9 & NA & NA \\
\hline Total $\mathrm{CO}_{2} \mathrm{e}$ emissions ${ }^{\mathrm{w}} \mathrm{t} / \mathrm{ha} /$ year & 17.2 & 18.9 & 21.3 \\
\hline $\mathrm{CO}_{2} \mathrm{e}$ emissions from the orchard soil ${ }^{\mathrm{v}} \mathrm{t} / \mathrm{ha} /$ year & 14.4 & 15.1 & 16.5 \\
\hline $\mathrm{CO}_{2} \mathrm{e}$ emissions from energy use ${ }^{\mathrm{u}} \mathrm{t} / \mathrm{ha} /$ year & 2.8 & 3.8 & 4.8 \\
\hline $\mathrm{CO}_{2}$ ratio $^{\mathrm{t}}$ & 1.1 & 1.2 & 1.2 \\
\hline Net $\mathrm{CO}_{2}$ sequestration $\mathrm{s}$ t/ha/year & 2.4 & 4.7 & 5.0 \\
\hline
\end{tabular}

${ }^{\mathrm{z}} \mathrm{y}+\mathrm{x}$.

${ }^{y}$ Carbon acquired in photosynthesis minus carbon released in respiration, expressed as carbon dioxide by multiplying with a factor of 3.67 .

${ }^{\mathrm{x}}$ The temporary nature of this stored carbon is considered in carbon emissions, which takes place during decomposition of the applied compost.

$\mathrm{w}_{\mathrm{v}}+\mathrm{u}$.

"Nitrous oxide emissions from orchard soil (from soil organic matter already present plus prunings and compost when applied) and carbon dioxide emissions from decomposed prunings and roots. In the kiwifruit system, $249 \mathrm{~kg} \mathrm{CO}_{2} \mathrm{e} / \mathrm{ha} / \mathrm{year}$ is in the form of nitrous oxide, $4 \mathrm{t} \mathrm{CO}_{2}$ e/ha/year is from decomposing compost and the balance is from prunings and roots. In apples, $394 \mathrm{~kg} \mathrm{CO}_{2} \mathrm{e} / \mathrm{ha} /$ year $(800$ trees/ha) and $122 \mathrm{~kg} \mathrm{CO}_{2} \mathrm{e} / \mathrm{ha} / \mathrm{year}(1200 \mathrm{trees} / \mathrm{ha})$ is in the form of nitrous oxide. The balance is respectively emitted from the prunings and roots.

${ }^{\text {u}}$ Carbon dioxide emissions from fossil energy use in management practices (direct and indirect). The direct energy is $21 \%$ for kiwifruit, $36 \%$ for semi-intensive apple, and 39\% for intensive apple systems. The balance is the indirect energy for the respective systems.

tRatio of $\mathrm{z}$ and $\mathrm{w}$. Indicates the carbon footprint (whether the organic orchard system is a net sink or source of carbon emissions)

${ }^{\mathrm{s}} \mathrm{Z}-\mathrm{W}$.

$\mathrm{NA}=$ compost not applied.

Source of data for calculations: Cornell University, 2007; Grogan and Matthews, 2002; Greer et al., 2003, 2004; Kroodsma and Field, 2006; Lakso et al., 2001; Page, 2009; Tustin, 2007; Wells, 1992, 2001.

Kerckhoffs and Reid, 2007). The results in this research therefore have implications for the horticultural industry so that commercial organic orchard systems, which are in full bearing age, can be considered as carbon sinks. However, the results are based on a single production year for five orchardists only. Including a higher number of organic orchardists and consideration to year-to-year variability in carbon sequestrations and emissions from the orchard systems will enable a more accurate estimation of the ability of the orchard systems to be a net carbon sink.

Comparison with other approaches to carbon footprinting. As a result of the pressure from governmental policies, public awareness, and consumer demands, protocols to measure the carbon footprints of various goods and services are being developed. Currently, there is a discussion of three standards that can guide the development of specific methodologies for carbon footprinting of goods and services. The first of these is the PAS 2050 of the British Standards, which was released in Oct. 2008 (BSI, 2008). The other two protocols are being developed by the International Standards Organisation and the World Resources Institute (MAF, 2009). Carbon footprinting as applied in this article is consistent with the PAS 2050 specifications and does not consider the fruits (kiwifruit and apples) as eligible products for storing carbon (BSI, 2008, Section 5.4.1).

It is suggested that carbon sequestration and emissions from soil should be excluded because there is considerable uncertainty regarding the impact of different techniques in agricultural systems (BSI, 2008, Section 5.6).
In this research, an attempt has been made to quantify carbon sequestration and emissions from orchard soil, thus indicating the orchard system's potential for net carbon sequestration. The finding from this research reinforces the idea that orchard crops have the potential to store carbon in their woody perennial growth and in the soil (Kerckhoffs and Reid, 2007; Kroodsma and Field, 2006). If the orchard system is a net carbon sink for a typical production year, then it can be expected to be the same for every other typical production year.

Perspectives to improve the proposed approach. The unavailability of secondary data for certain coefficients under New Zealand conditions is a gap in knowledge, which has to be filled through further research. The key coefficient that was taken from international sources was the parameter for soil carbon emissions relative to the decomposition of organic matter in the orchard. Previous studies suggest that soil is a major source as well as a sink of carbon in organic orchards (Page, 2009; Rahman et al., 2010). Following Grogan and Matthews (2002) it was considered that $18 \%$ of the carbon from mulched prunings and applied compost is sequestered in the soil and the rest is released back to the atmosphere in the same year. This coefficient was based on willow energy plantation systems in the United Kingdom because no similar information was available for orchard systems. This coefficient may either underestimate or overestimate $\mathrm{CO}_{2}$ emissions from orchard soils. Orchard crops such as kiwifruits and apples are pruned every year and might return more organic matter in the form of leaves and wood to the soil than the bioenergy plantations, which are harvested every 3 to 5 years. If this is the case, then the carbon that is estimated to be sequestered in the orchard soil in this research will be underestimated. On the other hand, orchard soils are more exposed to machinery traffic than willow bioenergy plantations, which might release more carbon relative to the carbon input in the orchard crops than the willow bioenergy plantations because of soil disturbance and organic matter oxidation. This might result in overestimation of the carbon sequestered in this research. This suggests that the lack of information on the parameter for soil $\mathrm{CO}_{2}$ emissions relative to carbon inputs from the orchard crops under New Zealand conditions is a gap in knowledge, which has to be filled through further research.

Second, delineation of the system boundary is important for deciding which processes are included or excluded from carbon footprinting. This research considered the orchard production stage and therefore the spatial boundary included processes until the fruit reached the packhouse. It is acknowledged that emissions are associated with subsequent shipping and the "food miles" (the distance the food travels as a measure of the impacts on the environment). The issue of food miles has drawn a lot of attention to New Zealand because of its geographical location relative to the European Union (EU), where most of its fruit is exported (Saunders et al., 2006). Organic fruit exports from New Zealand to the EU are bound to have carbon emissions associated with transportation and shipping, the exact value of the emissions depending on the mode of transport, namely air, sea, and/or road. The temporal boundary for carbon footprint estimation was a single production year. Ideally, carbon footprints based on LCA should consider the entire life cycle of an orchard system from establishment through to the fate of the orchard crops at the end of the life cycle (replaced after every 40 to 50 years). Such an integrated approach will yield more accurate results for carbon sequestration through the allocation of emissions and sequestrations over any single year. As more quantitative data become available, it may be possible to quantify the effects of management practices on long-term sequestration of carbon in orchard systems.

\section{Conclusions}

Carbon footprinting based on a net balance approach considered sources and sinks of carbon associated with orchard production and provided a better reflection of an orchard system's net contribution to climate change. Modeling carbon footprints enabled the estimation of the GHG emissions and sequestrations of otherwise complex orchard systems in a relatively simple way. This model suggests that the studied organic kiwifruit and apple systems have the potential to be carbon sinks over a typical production year. Modeling carbon footprints as applied in this research can therefore potentially yield a net benefit to 
New Zealand orchardists by earning them carbon credits. However, application of this approach to a higher number of organic orchard systems is essential to confirm the results. Similarly, consideration to year-to-year variability will enable to estimate the ability of orchard systems to sequester carbon during atypical years. Extending the temporal boundary over the lifespan of the orchard crops will give a more accurate picture of carbon footprints over any single year. Hence, further research to improve and validate the proposed approach is considered essential before it can be practically used for decision-making at the orchard level and for policymaking at the national level.

\section{Literature Cited}

Audsley, E. 1997. Harmonisation of environmental life cycle assessment for agriculture (No. Concerted Action AIR3-CT94-2028). Silsoe Research Institute, Silsoe, UK.

BSI. 2008. PAS 2050: Specification for the assessment of the life cycle greenhouse gas emissions of goods and services. 15 Mar. 2009. <http:// www.carbontrust.co.uk/carbon/briefing/premeasurement.htm>.

Cornell University. 2007. Apple rootstock fact sheets. 6 Jan. 2008. <http://www.hortnet.co.nz/ publications/proceedings/enzafd99/enza-01.htm>.

Dalgaard, T., N. Halberg, and J.R. Porter. 2001. A model for fossil energy use in Danish agriculture used to compare organic and conventional farming. Agr. Ecosyst. Environ. 87:51-65.

Di, H.J. and K.C. Cameron. 2002. Nitrate leaching in temperate agroecosystems: Sources, factors and mitigating strategies. Nutr. Cycl. Agroecosyst. 46:237-256.

Greer, D., C. Cirillo, and C. Norling. 2003. Temperature-dependence of carbon acquisition and demand in relation to shoot and fruit growth of fruiting kiwifruit (Actinidia deliciosa) vines grown in controlled environments. Funct. Plant Biol. 30:927-937.

Greer, D., A. Seleznyova, and S. Green. 2004. From controlled environments to field simulations: Leaf area dynamics and photosynthesis of kiwifruit vines (Actinidia deliciosa). Funct. Plant Biol. 31:169-179.

Grogan, P. and R. Matthews. 2002. A modelling analysis of the potential for soil carbon sequestration under short rotation coppice willow bioenergy plantations. Soil Use Manage. 18:175-183.

Horticulture New Zealand. 2007. Submission on sustainable land management and climate change: Options for a plan of action. 3 Dec. 2007. <http://www.hortnz.co.nz/communications/ pdfs/One_Submission.pdf $>$.

HortResearch. 2007. Fresh facts: New Zealand horticulture 2007. 18 Jan. 2008. <www.hortresearch. co.nz/files/aboutus/factsandfigs/ff2007.pdf>.

Kerckhoffs, L.H.J. and J.B. Reid. 2007. Carbon sequestration in the standing biomass of orchard crops in New Zealand. New Zealand Institute for Crop \& Food Research Ltd, Hastings, New Zealand. Report prepared for Horticulture New Zealand Ltd.

Kroodsma, D.A. and C.B. Field. 2006. Carbon sequestration in California agriculture, 19802000. Ecol. Appl. 16:1975-1985.

Lakso, A.N., M.D. White, and D.S. Tustin. 2001. Simulation modelling of the effects of short and long-term climatic variations on carbon balance of apple trees. Acta Hort. 557:473-480.

Lynas, M. 2007. Carbon counter. Harper Collins Publishers, Glasgow, UK.

MAF. 2002. Greehouse gas emission policies: Impact on agriculture. 6 Mar. 2006. $<$ http://www. maf.govt.nz/mafnet/rural-nz/sustainable-resourceuse/climate/greenhouse-gas-policies/httoc.htm>.

MAF. 2009. Greenhouse gas (GHG) footprinting strategy. 12 July 2009. <http://www.maf.govt. nz/climatechange/slm/ghg-strategy/>.

Meul, M., F. Nevens, D. Reheul, and G. Hofman. 2007. Energy use efficiency of specialised dairy, arable and pig farms in Flanders. Agr. Ecosyst. Environ. 119:135-144.

Milà i Canals, L. 2003. Contributions to LCA methodology for agricultural systems. Site-dependency and soil degradation impact assessment. PhD thesis.

Millennium Ecosystem Assessment. 2005. Ecosystems and human well-being: Synthesis. Island Press, WA.

Ministry for the Environment. 2005. New Zealand's greenhouse gas inventory 1990-2005. 21 Apr. 2007. <http://www.mfe.govt.nz/issues/ climate/greenhouse-gas-emissions/greenhousegas-inventory.html>.

New Zealand Government. 2009. Emissions trading bulletin. 15 Nov. 2009. <http://www.mfe. govt.nz/publications/climate/emissions-tradingbulletin-11/emissions-trading-bulletin-11.pdf $>$.

OECD. 1999. Environmental indicators for agriculture. Vol. 1. Concepts and framework. OECD, Paris, France.

OECD. 2001. Environmental indicators for agriculture. Methods and results. Vol. 3. OECD, Paris, France.

Page, G. 2009. An environmentally-based systems approach to sustainability analyses of organic fruit production systems in New Zealand. PhD Diss., Institute of Natural Resources, Massey University, New Zealand. <http://muir.massey. ac.nz/bitstream/10179/825/1/02whole.pdf > .

Rabl, A., A. Benoist, D. Dron, B. Peuportier, J.V. Spadaro, and A. Zoughaib. 2007. How to account for $\mathrm{CO}_{2}$ emissions from biomass in an LCA. International Journal of Life Cycle Assessment 12:281.

Rahman, M.H., A. Holmes, A. McCurran, and S. Saunders. 2010. Carbon sequestration in kiwifruit soils of New Zealand. Presented at the 19th World Congress of Soil Science, Soil Solutions for a Changing World; 1-6 Aug. 2010; Brisbane, Australia. 15 Oct. 2010. <http:/ www.iuss.org/19th\%20WCSS/symposium/pdf/ 0474.pdf>.

Saunders, C., A. Barber, and G. Taylor. 2006. Food miles-comparative energy emissions performance of New Zealand's agricultural industry: Report no 285. Prepared for New Zealand Ministry of Foreign Affairs and Trade, AERU, Lincoln University.

Shepherd, M., B. Pearce, B. Cormack, L. Philipps, S. Cuttle, and A. Bhogal, et al. 2003. An assessment of the environmental impacts of organic farming: A review for Defra-funded project OF0405 Retrieved Feb. 2006. 9 Oct. 2007. $<$ http://orgprints.org/6784/02/OF0405_909_ TRP.pdf $>$.

Statistics New Zealand. 2006. Agricultural production statistics (final) June 2005. 12 May 2007. <http://www.stats.govt.nz/store/2006/06/ agricultural-production-statistics-final-jun05-hotp. htm>.

Stolze, M., A. Piorr, A. Haring, and S. Dabbert. 2000. The environmental impacts of organic farming in Europe. Organic farming in Europe: Economics and policy. Department of Farm Economics, University of Hohenheim, Stuttgart, Germany.

Tustin, S. 2007. Rootstocks for intensive planting systems. 18 Jan. 2008. <http://www.hortnet.co. nz/publications/proceedings/enzafd99/enza-01. htm $>$.

Wells, C.M. 2001. Total energy indicators of agricultural sustainability: Dairy farming case study. Report to MAF Policy, Dept. of Physics, University of Otago.

Wells, G. 1992. Intensive/semi-intensive apples — The trial at Lincoln University: Proc. of Seminars, Jan./Feb. 1992. Dept. of Horticulture, Lincoln University, New Zealand.

Wiedmann, T. and J. Minx. 2007. A definition of carbon footprint. Research report 07-01. 2 Feb. 2008. <http://www.isa-research.co.uk>. 